\title{
An Alternative Early Field Experience for Physical Education Teacher Preparation
}

\author{
YuChun Chen ${ }^{1, *}$ \\ ${ }^{1}$ Western Kentucky University, 1906 College Heights Blvd, Bowling Green, Kentucky 42101, United States \\ *Corresponding author Email: yuchun.chen@wku.edu \\ DOI: https://doi.org/10.34256/ijpefs2214 \\ Received: 15-11-2021; Revised: 18-02-2022; Accepted: 20-02-2022; Published: 25-02-2022
}

\begin{abstract}
Implementation of early field experiences is a required component in nearly all teacher education programs because of the first-hand training in real-world situations that complement classroom learning. It is through the experiences that pre-service teachers have the platform to develop and demonstrate their competency in content knowledge, pedagogical skills, and professional dispositions. However, the onset of COVID-19 pandemic made it impossible to set up in-person early field experiences. The purpose of this study was to (a) describe an alternative early field experience planned and implemented to accommodate COVID-19 restrictions, (b) document what the participants learned throughout the experience, and (c) provided university faculty with suggestions for virtual early field experiences. Nineteen students enrolled in a 200-level physical education teacher education activity class in the Spring of 2021 submitted 10 weekly reports after watching self-selected videos that were related to soccer and volleyball. The duration of each video submission was analyzed using descriptive statistics. Data analyzed using the standard interpretive methods revealed three main themes. To identify their content knowledge acquisition, the participants described historical facts, abridged rules and regulations, sport-specific skills, strength and conditioning exercises, and tactical moves and team strategies. They also made game-related observations on the players, teams, and officials. Lastly, entertainment value was highlighted as a result of the freedom to choose the videos they were interested in. Suggestions for incorporating this early field experience and future research directions were discussed.
\end{abstract}

Keywords: Observation, Pre-Service Teachers, Competency, Virtual Field Placement



Dr. Chen is an Associate Professor in the School of Kinesiology, Recreation and Sport at Western Kentucky University. Her research areas include teaching and learning in physical education, physical education teacher education, and program evaluation. She has been teaching elementary and secondary physical education methods courses at her academic appointments, which give her the firsthand view of early field experiences planned and implemented for the benefit of her students.

\section{Introduction}

In physical education teacher preparation, field experiences are supplemental work done at $\mathrm{K}-12$ schools to enhance the knowledge and skills lectured in the classroom. At the beginning stage, pre-service teachers simply conduct non-participant, direct observation on physical education classes taught by inservice teachers. As pre-service teachers progress through the program, they are gradually given the opportunity to participate in the lesson delivery as teaching assistants and then team-teach small groups of students. These early field experiences (EFEs) in observing, assisting, and team-teaching eventually lead to student-teaching where pre-service teachers put knowledge and skills fully into practice by shadowing their mentor teachers during school days for a semester and teaching a class or two by themselves at 
the placement site. Completing certain amount of EFE hours before the student teaching semester is a required component in nearly all physical education teacher education (PETE) programs and a critical element in the national standards related to evidencebased accreditation. According to SHAPE America (2017), pre-service teachers are expected to demonstrate competency in Standard 1: Content and foundational knowledge, Standard 2: Skillfulness and health-related fitness, Standard 3: Planning and implementation, Standard 4: Instructional delivery and management, Standard 5: Assessment of student learning, and Standard 6: Professional responsibility by the time they graduate from the PETE program [1]. The EFEs and student-teaching semester at different K12 schools are an ideal training ground for meeting all standards as pre-service teachers interact with students, teachers, parents, and school personnel.

In the Spring of 2020, Coronavirus Disease (COVID-19) [2] attacked the world, and it has changed the way everyone lives ever since. According to van Kessel, Baronavski, Scheller, and Smith (2021), the COVID-19 pandemic had impacted Americans' job security, financial situation, personal relationships, how they spend their free time, how they perceive safety precautions, and so much more [3]. One of the drastic changes in education was how classes were delivered. Teachers were forced to move everything online and deliver the content virtually. It was a hustle having to upload all course content on a learning management system (e.g., Blackboard or Moodle) and use video conferencing technology (e.g., Zoom or Google Meet) to deliver the content over a short period of time. In the process, unfortunately, the quality of many courses suffered. Everyone stayed home when the pandemic first started in the Spring of 2020, so there was no field placement. Even when some of the restrictions were lifted during the 2020-21 academic year, many K-12 schools still did not allow pre-service teachers on campus unless they were student-teachers who practically were at the school with their mentor teachers every weekday. As a result of limited access to K-12 schools, university faculty had to be creative on setting up EFEs. The challenge came from keeping the experiences authentic and meaningful because the human interaction with the key players (i.e., students, teachers, parents, and school personnel) was missing. Alternative EFEs were still planned and implemented although some elements might be compromised in the delivery. In this paper, implementation of an alternative EFE in a teacher education activity class was described, what the participants learned from this
EFE was discussed, and suggestions for fellow PETE faculty were delivered.

Previous research has investigated pre-service teachers' competency in relation to the national standards [1], including content knowledge in lesson planning and implementation, pedagogical skills in instructional delivery and class management, and professional dispositions in the communication and interaction with students and teachers during EFEs [416]. Specifically, after conducting several observations and team-teaching two lessons at a junior high school, the 26 pre-service teachers in Barney and Christenson's (2009) study learned that they needed to work on their gym voice and should always overplanned or had a back-up plan for their lessons [5]. Moreover, the 39 third-year physical education majors in a secondary methods course indicated that quality planning and effective class management ensured student learning and led to successful lessons during the EFE [12]. In another example, the one-on-one experience working with students with disabilities helped the 71 pre-service teachers feel more satisfied and enthusiastic about the teaching profession as they continued to shape their professional attitudes, values and believes as physical educators [11].

In addition to pointing out what the pre-service teachers have learned during EFEs, previous research has also documented concerns and suggestions for improvement. One major concern was the lack of content knowledge in the subject matter $[4,8,10,12]$. The knowledge of sports is for sure the first and foremost quality to possess when it comes to teaching $a$ unit that ends with a culminating event. Rules of the game are usually presented in the beginning of a unit and constitute a great proportion of the cognitive learning domain. Other foundational and specialized knowledge such as physiological and biomechanical concepts is a vital component to teach skillful movement, physical activities, and fitness. Without the ability to teach the rules of the game or to explain the scientific principles of certain movement, pre-service teachers can and will eventually reveal their incompetence; consequently, lose the interest and attention of their students. Fellow scholars urged PETE faculty to emphasize the development of content knowledge and the application of such knowledge in the planning and observation stage before the actual implementation in the field [17-18]. Specifically, Erdman (1983) claimed that quality EFEs come from a connection between theory and practice [17]. When the university faculty fail to address or attempt to fill 
the "theory/practice gap", the EFEs are unlikely to be beneficial for the pre-service teachers. Goodman (1985) concurred Erdman's (1983) suggestion and added that field placements that allow pre-service teachers to experiment different aspects of teaching and learning criteria will help them make a better connection between theoretical knowledge and practical experience [18].

There is no doubt that pre-service teachers need the experience of working with students in the K12 physical education setting, but a few alternative EFEs reported in the previous research have proven to produce meaningful experience for them too. For example, as a service-learning project, the pre-service teachers in LaMaster's (2001) study acquired problemsolving and collaborative skills while teaching ultimate frisbee, pickleball and scoopball units to high school students [19]. Moreover, Everhart (2014) suggested that the experience of planning and implementing school-based intramurals has the potential to help preservice teachers develop communication and leadership skills, on top of the opportunity to teach sport-specific skills, tactics and strategies, as they interact with students in different sports [20]. Most recently, Chen (2021) proposed an innovative approach where the upperclassmen serve as the lead teachers in a physical education setting while each of the lowerclassmen pairs with a homeschooled child and goes through the learning process together [21]. This EFE appeared to be beneficial to the lowerclassmen as they identified specific behavior and skill performance of the homeschoolers, their own knowledge acquisition, and the unique characteristics of the program that they did not observe from other experiences [22].

As much as the alternative EFEs mentioned above could potentially develop knowledge and skills other than the competency addressed in the national standards [1], the onset of COVID-19 made it impossible for university faculty to set up in-person EFEs at K-12 schools during the 2020-21 academic year. Adapting to the latest trend where online learning has become the new normal, a virtual EFE cooperating with a local middle school and a high school was designed and carried out in the Fall of 2020 as part of the secondary methods course [23]. In this implementation, each pre-service teacher taught six physical education and two health lessons synchronously via Microsoft Teams. Several uncertain and unexpected events created additional challenges that would not have occurred if the experience was an in-person one. For instance, although they were both virtual instructions, teaching a lesson synchronously required a different skillset than teaching the same lesson asynchronously. The sudden policy change from the school district that all virtual lessons would be delivered synchronously and later transitioned to a hybrid format made the EFE like a rollercoaster ride [23]. The pre-service teachers were still under the training for basic skills in delivering content knowledge and practicing pedagogical content knowledge; adding unnecessary stress such as troubleshooting technology issues and adapting to last-minute schedule changes seemed to be too much and too soon for an EFE. Lawmakers have changed many policies that either cancel or delay requirements for quality learning in light of the pandemic. There is a need to explore different options to create meaningful EFEs based on the instructional experimentation in a given teacher education class [18]. Therefore, the purpose of this study was to (a) describe an alternative EFE in a teacher education activity class, (b) document what the participants have learned throughout the experience, and (c) provided fellow PETE faculty with suggestions for virtual EFEs.

\section{Materials and Methods}

\subsection{Participants}

Following the university's institutional review board approval, students enrolled in a 200-level teacher education activity class in the Spring of 2021 at the public research university in the southeastern United States were invited to participate in this research study. The students who gave consent included seven sophomores $(36.8 \%)$, eight juniors $(42.1 \%)$ and four seniors $(21.1 \%)$. Five of them were female $(26.3 \%)$ and 14 were male $(73.7 \%)$. Five of them were majored in health and physical education (HPE); hence, had other EFEs prior to this class, and the rest of the class were exercise and health promotion (EXHP) majors.

\subsection{Setting}

\subsubsection{Before COVID-19}

This 200-level teacher education activity class was designed for students to acquire knowledge and skills necessary to participate in team sports successfully. The class also had a focus on teaching strategies in team sports for school-age children. Before COVID-19, HPE majors were required to complete a minimum of 10 observation hours in any of 
the physical education classes at a predetermined school in their spare time. EXHP majors had the option to observe physical education classes at the same school or to observe practice sessions of a collegiate athletic team (team sports only) at the university, also on their own time. In order to expose students to different physical education classes/practice sessions and prevent them from completing most of the hours in one or two visits towards the end of the term, they were only allowed to log a maximum of two hours per visit. They reported the date, time and location of the visit, described what they observed during each visit, and asked the site supervisor for a signature on the same document. The purpose was for the HPE and EXHP majors to observe how team sport-related skills, tactics and strategies were performed by school-age children and young adults, and how they were taught by in-service teachers and coaches.

\subsubsection{After COVID-19}

In the Spring of 2021, this 200-level teacher education activity class was offered in person with half of the regular enrollment capacity to allow the recommended six feet of social distance in the classroom. For the hands-on part of the class, masks were required at all times in the 115-by-70-feet gymnasium, and antibacterial hand sanitizer was applied by everyone in class before and after the activities. Because the school district still did not allow pre-service teachers at any $\mathrm{K}-12$ schools unless they were student-teachers, an alternative EFE for this class was planned and implemented to accommodate the restrictions. Instead of physically attending a school site or a practice session on campus, the participants were to search on the Internet for a minimum of onehour video content and watch it each week for 10 consecutive weeks. They were given full autonomy to look for any video they were interested in watching, but the content had to be related to soccer for week 15 and volleyball for week 6-10. Each participant was not allowed to watch and report on the same video for different weeks. If a video was less than an hour in length, they were to find a few more to make up the one-hour requirement. For each video, the participants were instructed to (a) provide the hyperlink to the video, (b) explained why they chose this particular video, and (c) described three things they learned from the video content. There was no word limit on the weekly field experience report as long as the information provided was sufficient to convey their thought process. All participants submitted their weekly reports via Moodle no later than 11 o'clock on Friday evening. Those who missed the deadline could still submit their report via email to the course instructor, and late submission penalty applied.

\subsection{Data Collection and Analysis}

All video hyperlinks, reasons of choosing certain videos, and what they learned from the video content were retrieved from Moodle and transferred onto two separate Microsoft Word documents, one with the hyperlinks and another with the texts. Before any further analysis, all video links were checked for validness. When an invalid web address was detected, the participant who submitted the report was notified to correct the mistake. The duration of each video was then converted into seconds and entered onto a Microsoft Excel sheet. Descriptive statistics (i.e., minimum, maximum, mean and standard deviation) were conducted to summarize the quantitative data set. The qualitative data (i.e., reasons of choosing the videos and what they learned from the content), on the other hand, were analyzed using the standard interpretive methods of analytic induction and constant comparison in three stages [24]. In the first stage, all texts were carefully read; statements related to history, rules, skill development, training methods and game performance were highlighted. Stage two involved coding and categorizing the highlighted statements into different themes. In the third and last stage, statements that were categorized in the same theme during stage two were read repeatedly and compared with those in another theme, ensuring they were placed in the proper category and consistency in each theme was met. At the same time, relatively small categories were collapsed into overarching themes, which resulted in three main themes. Credibility and trustworthiness were secured by conducting a thorough search for negative and discrepant cases [24].

\section{Findings}

\subsection{Video Content}

A total of 231 videos were submitted by the 19 participants during the 10-week data collection period, and 23 of the videos were chosen and watched more than once by different participants. The top three most-viewed videos, reported by eight, seven and six participants, were all related to soccer skill development. Counting the repeated videos as one (meaning if a video was submitted eight times, it was only counted as one video), there was a collection of 180 videos. 
Table 1 Summary of Video Duration by Participant and Week



Note. ${ }^{+}$two videos; " three videos; ${ }^{*}$ four or more videos; --- no submission. 
Sixty-seven of the videos (37.2\%) were either full game replays or match highlights, 52 (28.9\%) were instructions and demonstrations for skill development, $25(13.9 \%)$ were compilations of best plays, ten $(5.6 \%)$ were strength and conditioning exercises, eight $(4.4 \%)$ was related to rules, seven $(3.9 \%)$ were regarding tactics and strategies, six (3.3\%) were volleyball anime, and five (2.8\%) were history-related videos or documentaries. The duration of each video submission by participant and week is illustrated on Table 1.

Most of the participants ( $n=15,78.9 \%)$ met the 10-hour field experience requirement (i.e., accumulated10 hours at the end), but only eight out these 15 received full credit for submitting a minimum of one-hour video every week and responding to the guided questions adequately, assuming they were all submitted on time. The "one hour (minimum) per week and 10 weeks total" criterion was to emphasize discipline and progression. Without this criterion, the participants who did not submit their reports weekly could end up earning the same grade as those who actually followed directions and did what was instructed. For example, Chris ${ }^{1}$ only submitted seven weekly reports, but the cumulative duration was almost an hour more than the required amount. Although it was roughly 13 minutes short, Deja almost met the 10-hour requirement with her five weekly submissions. Another observation from Table 1 revealed that a few of the participants had an exceeding number of hours at the end. Nate and Henry, for instance, reported more than 21 and 19 hours of videos, respectively. Both of their submitted videos were full game replays at the collegiate or professional level. Again, if the 10-hour cumulative duration was the only criterion to evaluate this EFE, as opposed to the 10 one-hour minimum weekly reports, some participants could submit a couple of three-hour long videos and be done with it. Unfortunately, it was nearly impossible to verify whether the participants actually watched the entire videos that they submitted. Regardless of the length, the participants could finish writing a report after watching the first five minutes of the video or skipping through it. The participants were entitled to the benefit of the doubt assuming that they did fulfill the screen time as they would to observe an in-person physical education class or practice session. Readers may consider Table 1 as a reference and acknowledge that the reasons of choosing certain videos and what they had learned from the content were more meaningful in this EFE.

\subsection{Identified Themes}

Unlike the previous setup where the HPE and EXHP majors in this class were limited to observe a K12 physical education class or a colligate team's practice session to complete their hours, the participants in the same class underwent the EFE with the freedom to choose the content they were interested in as long as it was related to soccer and volleyball. Based on the reasons they chose the videos and what they had learned from the content, three main themes were identified: content knowledge acquisition, game-related observations, and entertainment.

\subsection{1-1 Content knowledge acquisition: History and rules}

Out of the 180 videos, five showed the evolution of soccer or volleyball, the international governing body of the sport, and a few well-known players. In addition to describing the forementioned facts, the knowledge acquisition in the historical aspects was also referenced to make a connection with rules and game performance. Isaiah wrote, "I wanted to know the history of soccer to better understand how the game works and how it is supposed to be played properly" (EXHP major, week 4). Noah also made a similar note in his earlier report:

I chose this video because I do not know much on the history of soccer. Typically, with other sports, when I learned more about its history, I began to understand the game more and why it has the rules that it does. I believe learning more about soccer's history would help me understand the game more. (EXHP major, week 2)

Located in a community where American football and basketball were the predominant sports, soccer and volleyball appeared to be quite foreign to some participants. While two admitted their lack of experience in soccer: "I have very little experience with soccer and do not understand how the game is entirely played" (Noah, week 1) and "I have never played soccer before, so it is a new concept for me" (Maddie, EXHP major, week 1)", Sofia claimed that her lack of knowledge in volleyball was from the unpopularity of the sport in her birth country: "I knew very little about volleyball since it is not a very popular sport in Norway" (EXHP major, week 7). These participants intentionally looked for videos to further their knowledge in the general rules and regulations, including but not limited to, field/court dimensions, 
equipment and playing positions. Jacob wrote, "there is a coin toss before the game players can pass the ball to their own goalie. Minutes can also be added to the end of the current minutes of the game" (EXHP major, week 5). Chris also reported, "a match is 3 sets of 25 and each team must win a set by 2 points when the blockers block a spike, they can hit it again each team has 2 timeouts per set" (EXHP major, week 7). Jada's report covered more details with a few differences between men's and women's matches:

There are six players on each side. The players use their hands to bat a ball back and forth over a high net, trying to make the ball touch the court in the opponents' playing area before it can be returned one of the differences between men's and women's volleyball is the net height. Men's net height is 2.43 meters and women's is 2.24 meters. This is because men in general are taller and can jump higher than women, so the higher net makes it more challenging. (EXHP major, week 1)

The most mentioned playing position of all was the back-row defensive specialist in volleyball called libero. The participants either highlighted the libero position in the videos of basic rules or purposefully found a video about the position to watch. Examples of how the participants described this playing position are illustrated in the following data passages:

I noticed that there was a girl in a different color jersey and I didn't know what her role of the team was. After doing some research, I discovered that this player is called the libero and they typically have the best ball control. I also learned that the libero stays on the back row during the game. (Chris, week 6)

I did not know that there were so many different roles on the court, and that each position has different rules to follow. In this video, I learned that the libero is a back-row player who is specialized in defense. This player can sub in and out as much as it wants to (therefore the word libero, which means "free"). The libero is typically the best passer and specializes in receiving serves and kills from the opposing team. (Sofia, week 9)

\subsection{1-2 Content knowledge acquisition: Skill development}

The participants who chose to watch tutorial videos on different soccer and volleyball drills expressed the intention to improve their skills and game performance. For instance, Ben "picked the videos to learn some drills [he] can do this weekend in the house to get [him] more prepared for the upcoming skills test" (EXHP major, week 5). Maddie, on the other hand, "hoped to make a goal in one of the games [they] play in class and hope this video will show [her] how to do that" (week 2). Many of them managed to describe the video footage from the visual and audio context to the written form:

The $7^{\text {th }}$ skill in this tutorial was called the Neymar Flick, which is a misdirection move to make the defender think you are going to make a 180 degree turn and go back the same direction. This move will be very effective for creating space against defenders. The $14^{\text {th }}$ skill was the Thiago Feint, which is where you fake kick outside then go inside. The fake kick outside will get the defender off balance then create space for you inside. The $33^{\text {rd }}$ skill is the Cruyff Turn, which is used to change direction. It is used to cause misdirection and make a smooth turn after. (Lucas, HPE major, week 2)

I learned how to jump float serve in this video. First, have the ball in front, arm extended out and toss the ball in the air while jumping and swinging your opposite hand and follow through to send the ball over the net. I also learned how to become a better passer. Stay squatted, shoulder length apart before the ball comes and use both hands closed together to bump under the ball while communicating with teammates that you are passing too. (Niles, EXHP major, week 7)

Some other participants who chose skill-related videos demonstrated their comprehension during the learning process. In their reports, not only did they describe the "what", but they also identify the "why" for their own skill improvement or for their team's game performance:

This video showed me how to use an easy move against defenders and get them going in the opposite direction before shooting a goal. You have to shift the defense in order to create a lane for a goal. You have to have a firm, planted leg before you kick and follow through. You have to be flexible in your foot and ankles in order to have control of the ball while performing those moves. Also, you have to be able to change your direction rapidly and use your body to protect the ball against defenders. (Jacob, week 3 )

I wanted to have more knowledge about serving and serve receiving in volleyball. It is partially true that if a team wins the serve and serve receiving battle, that team is going to win the match. Our team does not serve or receive very well, and we lost most 
of our games because of that, so I think it is important that we practice serving and receiving more in class. (Drew, EXHP major, Week 7)

Instead of describing multiple skills in general, some participants chose to emphasize on a specific concept or technique regarding the skill development. These reports were the results of a misconception prior to taking this teacher education activity class or a surprise after learning it the correct way. The "timing" content was brought up by several participants; whether it was a pass, a shot or a save in soccer, or a serve, spike or block in volleyball, these participants wrote their reports as they were learning the concept for the first time. Two examples, one on a misconception in soccer and another on a "new" concept (at least for Henry) in volleyball, are illustrated in the following data snippets:

I learned the importance of drills on the nondominant leg. For a right-handed/footed person, I thought you would need to train the right leg primarily because of the striking action on that foot. Typically, when you strike a ball with your right foot, you balance on your left leg. But when striking with your left foot, you are thrown off due to your lack of balance and coordination on your right leg. It has little to do with kicking with your left foot, but the balance and coordination of your right leg. (Noah, week 1)

This play caught my attention because the first forearm pass from the Chinese player was not accurate and caused the setter to touch the net and lose that point. There is another play that the same Chinese player made an accurate pass to the setter, and this time the setter set up for a block and got an easy point for the team. I learned that you need to have an accurate first pass to have a chance to score offensively. I didn't know how important the first pass was and it's the basic forearm pass that we have been working on this whole time. (Henry, HPE major, week 10)

\subsection{1-3 Content knowledge acquisition: Strength and conditioning}

Some proactive participants also declared the importance of additional training in strength and conditioning as they came side-by-side with skill development and were the key components to improve game performance. They hand-picked videos on the training strategies for cardiovascular endurance and muscular strength designed specifically for soccer and volleyball players:
I chose this video because it gave me an idea of how strength and conditioning programs may be designed during a soccer season. I learned that the main training components are linear speed, change-ofdirection ability, plyometrics, explosive/loaded power, and intermittent endurance. Each of these components plays a huge role in the ability/skill level of soccer athletes. They are the driving points that set the athletes up for success in the sport. (Camila, HPE major, week 3)

In video two, I noticed she did a lot of jumping, core, and shoulder exercises. She performed jumping jacks, planks, shoulder taps, and lifts. A few of the exercises she performed were very similar to the exercises in video one, but some were new to me. This really shows what exercises are important to help you better your body for volleyball. (Maddie, week 9)

\subsection{1-4 Content knowledge acquisition: Tactics and strategies}

Also noteworthy to the content knowledge acquisition were the tactical moves and team strategies in soccer and volleyball. According to Mitchell and Walton-Fisette (2016), "whereas strategy refers to an overall game plan, tactics refers to the moment-tomoment adjustments that players make to solve the problems presented by the game" (p. 58-59) [25]. Most comments coded under this sub-theme were associated with tactical moves. From both the tutorial videos and full game replays, the descriptions about how soccer players were constantly moving with or without the ball to create passing lanes and lanes to the goal, how they paid attention to where their teammates and opponents were to create open space for setting up a play, and how they would intentionally kick the ball to their own goalies to reset a play were reported. As for volleyball, the reports were predominantly referred to the drills to train setters and their performance during gameplay because this role appeared to have more control over making momentto-moment adjustments than any other playing positions. Examples of the tactical moves and team strategies are illustrated in the following data extracts:

I noticed many players kicking their own ball out of bounds intentionally. After looking more into this, I realized that most of the time it is because the team is not in a good position to score so they will use that to "reset." I also gathered from this video that the team kicks the ball back to their own goalie very often, and I think it is for the same reason. (Chris, week 2) 
The first video showed me how to train setters. The setter's feet should be open to the court. The hips and head should be neutral when setting. I learned that it is important to be creative. When setting up for a spike, instead of setting the ball up in front up the setter, it can be set behind [the setter] to catch the opposing team off guard. I learned that, in order to score, you need to set the ball up differently according to where your teammates are and where the opponents stand. (Aaron, HPE major, week 10)

There are two types of defense in soccer, which is man to man and zonal defense. Depending on the experience level of the players that make up the team and the situation, the coach decides what defense the team should run. Zonal defense is when the team operates in an organized defensive formation such as a 4-4-3. Man to man defense is when each player individually guards an assigned or self-assigned player from the opposing team. (Drew, week 5)

Volleyball is a team sport. Everyone needs to communicate and know where they are on the court to make a play. Immediately after the ball is served, depending on where they stand and what play they're trying to do, everyone moves quickly to their designated spots. For example, if a team tries to set the ball up for an outside hitter and she stands on the right side, the players need to switch up their positions for her to run to the left side while someone else covers her spot. (Jada, week 8)

\subsection{2-1 Game-related observations: Players and teams}

The second main theme included comments and notes that were unrelated to the rules and skill development of soccer/volleyball or the tactics and strategies of the game, but still considered meaningful experiences learned from this EFE. The behaviors described here were not necessarily associated with game performance such as pass success percentage in soccer or blocks per set in volleyball; rather, they were routines of individual players or interactions of the entire team during gameplay. For instance, a soccer player may adjust his uniform a certain way before charging for the penalty kick or a volleyball player may bounce the ball twice and spin the ball in her hand before tossing it up in the air for the serve. In terms of team atmosphere, Isaiah noticed "the [volleyball] players usually huddle up after every point" (week 10), Chris pointed out "both teams' benches are standing up the whole match cheering on their teammates" (week 10), and Lucas claimed that volleyball players seemed to "dive for every ball. . . and never give up on a play" (week 8). Another general comment was made by multiple participants regarding the location where volleyball players started their servers. Examples of this observation are illustrated in the following data excerpt:

I am noticing about this game is how far back the athletes are starting their serves. I was always under the impression you had to start on the back line to serve the ball. However, they start way back behind the line and kind of charge their way forward. It's like they put so much power in their serves they have to start further back so their ball stays in bounds. (Deja, HPE major, week 7)

Another thing I noticed was how far away the server started their serve. Serving will be something a little more complicated for me to get the hang of just because I'm used to serving a volleyball as you would playing tennis, which is standing behind the line and serve stationary. (Ben, week 7)

\subsection{2-2 Game-related observations: Comparison of intensity}

From watching the full game replays or match highlights, the level of intensity was compared between men's and women's volleyball matches. Ben mentioned in this week 9 report that he watched a women's college game last week "and this week [he] wanted to see if there were any differences in men's game. [He] noticed that the [male] players move faster, jump higher and have more power." Chris made a similar comment in this week 7 report:

I learned that men's match is much more aggressive and intense than women's. This was my first men's match to watch, and they hit much harder, seemed to rally and set more, so in my opinion, men's volleyball was much more enjoyable and had more action packed than some of the other women's games I have watched.

The level of intensity was also compared at different levels of competition. Obviously, the intensity was minimal at the high school level, and it became more and more intense from the collegiate to the professional level. Comments similar to "the pace of play is not near as fast in high school compared to college" (Aaron, week 8), "how much quicker the plays are in college volleyball compared to a high school level" (Deja, week 8), and "there were definitely more quick spikes at the professional level than the college games I watched for the past two weeks" (Jada, week 
10) were made throughout the second half of the EFE. The intensity level in soccer, on the other hand, was referenced as "too much running back and forth on the field" (Camila, week 4) or "a lot of pushing around and body contacts" (Ryan, EXHP major, week 8). Since the soccer games watched and reported by the participants were all men's matches at the professional level, the intensity was compared with one of the popular sports in the state. Isaiah commented, "soccer can be more physical than American football. There is a lot of running, pushing and kicking in soccer. This can lead to injuries on both teams" (week 3). While the participants were amazed by the intense game atmosphere, they noticed that unforced errors still occurred at the highest level of performance:

What I learned in this video is how swiftly Messi was able to steal the ball from the other players, but he missed a penalty kick. I learned that even some of the best players have mess ups. A few other players made some mistakes in the game, but later made perfect passes or goals. (Maddie, week 5)

The next thing I noticed was they still made mistakes. The main mistake they made was to use too much power and plant the ball on their own side or out of bounds. Nobody is perfect. Even the best of the best like these guys that are competing for their country missed serves. (Ben, week 9)

\subsection{2-3 Game-related observations: Officials}

Players were not the only people who the participants watched during the game. The game officials were also getting the participants' attention and taught them a few things. Jacob chose a full soccer game to learn not only "how professional players play the game" but also "how to properly officiate a soccer game as a referee" (week 2). Jacob later in the same report described the different positions where the referees were supposed to be during the game. While also watching the officials in a soccer game, another participant put himself in their shoes and reflected on the following data snippet:

I learned that it would be very difficult for me to call some plays out of bounds. I am an umpire for baseball so watching other sports leads me to watching officials. It does not seem to be enough of them in soccer and with a field this big, it would be very difficult to be a good ref. I also never realized how close the ball could get to going out of bounds without it being called out of bounds. (Chris, week 5)
As for volleyball, several participants made a note on the high platform that the officials stand on during the game. This observation was a new piece of information to the ones who had never played or watched volleyball before. Ben wrote, "the referees were up high above the net. Although we do not have these tools for class, I can see how this is beneficial for the referee to see everything more clearly" (week 7). Moreover, Caleb (EXHP major) in this week 9 report revealed that he enjoyed "seeing the referee give hand signals and knew what most of them meant" and he also pointed out how the four officials worked together during the game:

All of the referees are in sync. Every signal that they make is made at the same time and looks very official. I also appreciate how the first ref looks at the second ref and line judges to confirm what he saw before making a call. With this being said, the line judges are always giving him a signal and never leaving him without a sign.

\subsubsection{Entertainment}

Since there was no specific restriction on the content selection for this EFE other than it had to be soccer-related during week 1-5 and volleyball-related during week 6-10, some participants watched full game replays, match highlights, compilations of best plays, or Japanese anime for pure entertainment. These participants were amazed by the players' highly skilled performance and the perfect executions produced by teamwork and communication. They thought it was entertaining to see elite players such as Cristiano Ronaldo and Lionel Messi doing fancy footwork with the ball. They also expressed the enjoyment of watching impressive digs, powerful spikes, and seamless pass-set-attack rallies. In the video that showed "some of the coolest soccer skills and tricks", Chris explained that "a meg was when the ball went between the defender's legs" and he "got a kick out of it because [he] thought it was funny and embarrassing at the same time" (week 5). Deja made a similar comment in her week 2 report: "players kick the ball through their opponents' legs. This doesn't seem to be a hard skill compared to the rest in the video, but it amazes me how many professional players still fall prey to this maneuver." Examples of other entertainment sources are illustrated in the following data passages:

I really enjoyed this video, and it showed a lot of star players with so many great soccer skills. Cristiano Ronaldo was shown in the video a lot and I 
was impressed with his skill set. Soccer is more than a sport for some people. It's a part of their cultures. I think this video was really interesting to watch because the fans made me want to watch a professional soccer game one day just to get the overall experience. (Jada, week 5)

Everything happened so fast that it was hard to keep up. Both teams had really good digs, blocks, and spikes to keep their team alive. I also find it crazy how neither team touched the net with all those blocks and spikes. It didn't seem to be two hours after I watched the game because there were so many actions that caught my attention. (Nate, EXHP major, week 8).

It was noticeable that the match highlights and compilations of best plays really brought some special effects to the participants' experience in soccer. Evidently, selected moments edited in one video with upbeat background music did nothing but got them excited. Ryan thought that "they did a good job with the video. There are different clips of Cristiano Ronaldo in the video. They have multiple celebratory goal slides and a lot of beat drops in the video" (week 4). Aaron also made a note on the same idea: "In this video, I am shown some really good soccer clips dropping to the beat of the music, which makes it super fun to watch" (week 2). Besides, it was interesting to see how the edited videos could change their minds about the sport and motivate them to do better. Drew admitted that "before learning anything about soccer, I had considered it boring due to the lack of scoring that takes place in it. But now I realize that watching players execute these moves and trick opponents is entertainment in itself" (week 4). Another participant also felt the same way:

It's really inspiring to see all these amazing soccer players in one video. This video was very motivating and I truly enjoyed how the clips were put together. The video wasn't very informational but more on the side of getting people excited about the sport and motivating them to want to become their very best. (Sofia, week 5)

\section{Discussion}

In the present study, the participants were able to describe historical facts in soccer and volleyball, explain abridged rules and regulations, process sportspecific skills in their own words, identify the strength and conditioning exercises that would be helpful for skill development and game performance, and make sense of the tactical moves and team strategies during gameplay. The considerable amount of content knowledge reported by the participants suggested that this alternative EFE could be incorporated in the PETE courses to address pre-service teachers' competence in the first standard for evidence-based accreditation [1]. This finding also served as a potential solution to the concern addressed in the previous EFEs [4, 8, 10, 12]. After all, content knowledge is an essential component that all physical education teachers should possess in order to plan and implement quality lessons.

This alternative EFE also gave the participants an opportunity to explore more aspects in the sports than the previous setup could offer in a $\mathrm{K}-12$ physical education class or a collegiate team sport practice session. The participants were able to identify meaningful observations on the players' highly skilled performance, the teams' perfect executions, and the officials' positions and skills during gameplay. They also expressed the entertainment value as a result of the freedom to choose the videos they were interested in. Although these outcomes were not necessarily aligned with the competency expected of pre-service teachers [1], they did contribute to SHAPE America's (2013) K-12 physical education Standard 5: The physically literate individual recognizes the value of physical activity for health, enjoyment, challenge, selfexpression and/or social interaction [26]. These full game replays, match highlights, and compilations of best plays with upbeat background music could be utilized as the resources to introduce a new unit, motivate student learning, and expand the existing knowledge base.

Compared to the other alternative EFEs planned and implemented previously [19-20, 22], this EFE was set up without school-age children or youth, which did not help PETE programs to close the theory/practice gap [17-18]. However, this alternative EFE could be a lead-up to the elementary and secondary methods courses. Specifically, PETE faculty could require pre-service teachers to fulfill a certain number of hours in watching videos of history and rules as well as skill-related instructions and demonstrations before planning a lesson and sending them to work with students in a physical education class. Additionally, this EFE could help overcome the challenges in the delivery of virtual lessons [23]. As pre-service teachers continue to acquire knowledge and skills in teaching quality physical education, having them attend webinars or watch videos on the tools and strategies to deliver virtual and hybrid lessons would 
be a beneficial skillset to possess in the era of technology. Another downside of this EFE was not having a way to verify the participants' actual time spent in watching the videos. As mentioned before, the participants could compose their weekly reports without watching every second of the videos. Nevertheless, any pre-service teachers could be sitting in a physical education class and paying no attention to the lesson during the one-hour observation, which probably produced a similar, if not worse, report compared to the requirement of watching a one-hour video for this alternative EFE.

There were a few limitations for the present study. First, there was only one data source, which was the weekly reports. Future research should include other data sources such as semi-structured interviews or course-related documents. A variety of data sources could help increase the validity and reliability in qualitative research. Besides, the sample was inclusive of a single PETE program in the southeastern region of the United States, which narrowed the perspective and should not be generalized to all PETE programs around the country. Fellow researchers could implement this alternative EFE in another type of PETE classes and/or at a different institution, which would help confirm or deny its effectiveness in helping pre-service teachers achieve competency in acquiring content knowledge. The last suggestion for future research is to follow up with the same group of pre-service teachers who have gone through this alternative, virtual EFE. An investigation on the pre-service teachers' ability to carry out the content knowledge and demonstrate their competency in the planning and implementation phases of the PETE program could be vital to determine the effectiveness of this EFE.

\section{Conclusion}

It is a fair statement to say that there is not a perfect EFE in physical education; in fact, no perfect EFE exists in education. University faculty should recognize that students, classes, and teaching situations are different, and the one-size-fits-all approach never works. There is a need for consistent changes in designing a feasible EFE that helps preservice teachers develop their competency in content knowledge, pedagogical skills, and professional dispositions. This need is even more critical as the global COVID-19 pandemic has significantly limited the accessibility for pre-service teachers to earn EFE hours at school settings. Along with the traditional [4-16] and non-traditional EFEs [19-20, 22-23] reviewed in the introduction section, this article described an alternative EFE that is fulfilled virtually as well as the positive outcomes and a few drawbacks of implementing such virtual EFE. University faculty may use this non-traditional EFE in the 100- and 200-level teacher education courses as a lead-up to the EFEs in the elementary and secondary methods courses that typically require pre-service teachers to observe, assist, and teach live students.

\section{References}

[1] National Standards for Initial Physical Education Teacher Education, SHAPE America - Society of Health and Physical Educators, (2017). Retrieved from:

https://www.shapeamerica.org/accreditation/upl oad/National-Standards-for-Initial-Physical-

Education-Teacher-Education-2017.pdf

[2] Coronavirus disease (COVID-19), World Health Organization, (n.d.). Retrieved from https://www.who.int/healthtopics/coronavirus\#tab=tab 1

[3] P. Van Kessel, C. Baronavski, A. Scheller, A. Smith, In their own words, Americans Describe the Struggles and Silver Linings of the COVID-19 Pandemic, Pew Research Center, (2021). https://www.pewresearch.org/2021/03/05/intheir-own-words-americans-describe-thestruggles-and-silver-linings-of-the-covid-19pandemic/

[4] P.C. Allison, What and How Preservice Physical Education Teachers Observe During an Early Field Experience, Research Quarterly for Exercise and Sport, 58 (3) (1987) 242-249. [DOI]

[5] D. Barney, R. Christenson, Physical Education Majors Team Teaching in an Early Field Experience in a Junior High School Setting, Asian Journal of Physical Education \& Recreation, 15(2) (2009) 16-21. [DOI]

[6] D. Barney, F. Pleban, Pre-service Physical Education Teacher's Perceptions of Teaching Before and After a Semester Long Elementary Physical Education Practicum Experience, Physical Educator, 63 (2006) 46-52.

[7] W. Chen, Learning the Skill Theme Approach: Salient and Problematic Aspects of Pedagogical Content Knowledge, Education, 125 (2) (2004) 194-212.

[8] M.D. Curtner-Smith, The impact of an Early Field Experience on Preservice Physical Education Teachers' Conception of Teaching, Journal of Teaching in Physical Education, 15 (2) (1996) 224-250. [DOI]

[9] E. Eldar, Effect of Self-Management on Preservice Teachers' Performance During a Field 
Experience in Physical Education, Journal of Teaching in Physical Education, 9 (4) (1990) 307-323. [DOI]

[10] C. Ingersoll, J.M. Jenkins, K. Lux, Teacher knowledge development in early field experience, Journal of Teaching in Physical Education, 33 (3) (2014) 363-382. [DOI]

[11] T.E. Layne, J. Blasingame, Analysis of a Physical Education Teacher Education Field Experience of Working One-on-One with Students With Severe and Profound Disabilities in a Self-Contained Environment, Physical Educator, 75 (4) (2018) 683-700. [DOI]

[12] M. O'Sullivan, N. Tsangaridou, What Undergraduate Physical Education Majors Learn during a Field Experience, Research Quarterly for Exercise and Sport, 63 (4) (1992) 381-392. [DOI]

[13] E.G. Ralph, Developing Professional Attributes among Student Teachers during Field Experience Programs, Education Canada, 29 (1) (1989) 3240.

[14] A.R. Ramos, K. Esslinger, E. Pyle, The Effects of Field Experience on Delivery of Feedback, The Physical Educator, 72 (5) (2015) 278-287. [DOI]

[15] I. Rovegno, Learning to teach in a field-based methods course: The development of pedagogical content knowledge, Teaching and Teacher Education, 8 (1) (1992) 69-82. [DOI]

[16] A. Sebren, Preservice Teachers' Reflections and Knowledge Development in a Field-Based Elementary Physical Education Methods Course, Journal of Teaching in Physical Education, 14 (3) (1995) 262-283. [DOI]

[17] J.I. Erdman, Assessing the Purposes of Early Field Experience Programs, Journal of Teacher Education, 34 (4) (1983) 27-31. [DOI]

[18] J. Goodman, What Students Learn from Early Field Experiences: A Case Study and Critical Analysis, Journal of Teacher Education, 36 (6) (1985) 42-48. [DOI]

[19] K.J. LaMaster, Enhancing Preservice Teachers Field Experiences through the Addition of a Service-Learning Component, Journal of Experiential Education, 24 (1) (2001) 27-33. [DOI]

[20] K. Everhart, Using School-based Intramurals as Early Field Experiences for Physical Education Teacher Education Majors, Journal of Physical Education, Recreation \& Dance, 85 (9) (2014) 44-46. [DOI]

[21] Y. Chen, Kill Two Birds with One Stone: Two PETE Courses Exploring Experiential Learning in One Early Field Experience, Journal of Physical
Education, Recreation and Dance, 92 (9) (2021) 18-23. [DOI]

[22] Y. Chen, Kinesiology majors' perceptions of an early field experience with the homeschoolers, Journal of the Louisiana Association for Health, Physical Education, Recreation, and Dance, 84 (2020), 1-13.

[23] C.A. Webster, J. Moon, H. Bennett, S. Griffin, Implementation and effectiveness of a CSPAPinformed, online secondary methods course with virtual field experiences during the COVID-19 pandemic, Journal of Teaching in Physical Education, 40 (3) (2021) 508-515. [DOI]

[24] J.P. Goetz, M.D. LeCompte, (1984) Ethnography and Qualitative Design in Educational Research, Academic Press, Massachusetts, United States.

[25] S.A. Mitchell, J.L. Walton-Fisette, (2016) The Essentials of Teaching Physical Education: Curriculum, Instruction, and Assessment, Human Kinetics.

[26] Grade-level Outcomes for K-12 Physical Education, SHAPE America - Society of Health and Physical Educators, (2013). Retrieved from: https://www.shapeamerica.org/uploads/pdfs/20 17/Grade-Level-Outcomes-for-K-12-PhysicalEducation.pdf

\section{Acknowledgement}

The author received no financial support for the research, authorship, and/or publication of this article.

\section{Ethics Approval}

Approval was sought from Institutional Ethics committee

\section{Informed Consent}

Written consent was obtained from participants

\section{Availability of data and material}

No additional data are available.

\section{Conflict of interest}

The Author has no conflicts of interest to declare that they are relevant to the content of this article.

\section{Does this article screened for similarity?} Yes

\section{About The License}

(C) The author 2022. The text of this article is open access and licensed under a Creative Commons Attribution 4.0 International License 